\title{
The secret life of deep-sea shrimps: ecology and evolution clues from the larval description of Systellaspis debilis (Caridea: Oplophoridae)
}

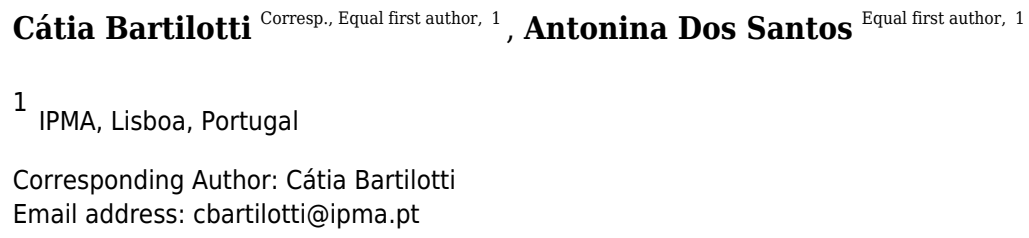

Currently there are 21 shrimp species in the northeastern Atlantic and Mediterranean Sea which are considered to belong to the superfamily Oplophoroidea, but the larval development is unknown for most of them. The complete larval development of Systellaspis debilis (A. Milne-Edwards, 1881), here described and illustrated, is the first one to have been successfully reared in the laboratory, consisting of four zoeal and one decapodid stages. The zoeae were found to be fully lecithotrophic, which together with the females' lower fecundity, are probably evolutionary consequences of the species mesopelagic habitat. 


\section{The secret life of deep-sea shrimps: ecology and \\ 2 evolution clues from the larval description of \\ 3 Systellaspis debilis (Caridea: Oplophoridae)}

4

5 Cátia Bartilotti \& Antonina dos Santos

6

7 IPMA, Av. Dr. Alfredo Magalhães Ramalho, 6, 1495-165, Algés, Portugal

8

9 Corresponding Author:

10

Cátia Bartilotti

IPMA, Av. Dr. Alfredo Magalhães Ramalho, 6, 1495-165, Algés, Lisboa, Portugal

Email address:_cbartilotti@ipma.pt

\section{Abstract}

Currently there are 21 shrimp species in the northeastern Atlantic and Mediterranean Sea which are considered to belong to the superfamily Oplophoroidea, but the larval development is unknown for most of them. The complete larval development of Systellaspis debilis (A. MilneEdwards, 1881), here described and illustrated, is the first one to have been successfully reared in the laboratory, consisting of four zoeal and one decapodid stages. The zoeae were found to be fully lecithotrophic, which together with the females' lower fecundity, are probably evolutionary consequences of the species mesopelagic habitat.

\section{Introduction}

Systellaspis debilis is a mesopelagic shrimp belonging to the family Oplophoridae, occurring in the Atlantic and Indian Oceans (e.g. Lunina, Kulagin \& Vereshchaka, 2018). Even though a lot is known about the mesopelagic community and its function in marine ecosystems, much remains unknown, especially for the crustacean species. However, oplophorid shrimps and their larvae gained attention recently with the application of molecular techniques to the phylogenetic systematic studies of Caridea. Wong et al. (2015) provided the molecular data to support the resurrection of the family Acanthephyridae by Chan et al. (2010), retrieving two major clades within the Oplophoroidea, the Oplophoridae and the Acanthephyridae. Recently, Lunina, 
32

33

34

35

36

37

38

39

40

41

42

43

44

45

46

47

48

49

50

51

52

53

54

55

56

57

58

59

60

61

62

63

64

65

66

67

68

69

Kulagin \& Vereshchaka (2018) presented the most comprehensive phylogenetic analyses for this group to date, using morphological and molecular data, showing four robustly supported species groups within the genus Systellaspis.

Seventy years earlier, Gurney \& Lebour (1941) suggested oplophorid species two groups according to the size of the eggs and the number of zoeal stages in the life cycle: the first group including the genera Oplophorus, Systellapis, Ephyrina and Hymenodora having large lipidfilled eggs and five or fewer zoeal stages, and the second group, with the genera Acanthephyra, Meningodora and Notostomus having small eggs and nine or more planktotrophic stages. Previously Kemp (1907) noticed that S. debilis had much larger eggs and their newly hatched larvae were more developed than those of Acantephyra purpurea. The egg size is an important aspect of the life history of marine organisms, with large eggs generally reflecting an increased maternal investment (e.g. Moran \& McAlister, 2009).

Of the 16 valid species of Oplophoridae Dana, 1852, only two larval sequences collected from plankton have been described: five zoeal stages and one decapodid for Oplophorus spinosus, and, four zoeal stages and one decapodid for Systellaspis debilis, both by Gurney \& Lebour (1941). S. debilis first zoeal stage is described as having a small rostrum, eyes large and sessile, all pereopods and pleopods present as buds, a broad telson with a small median indent with $7+7$ spines fringed with spinules, and the uropods visible under integument (Gurney \& Lebour, 1941). The second stage is presented as having eyes stalked, the peduncle of the antennule 3 -segmented, the telson with $8+8$ spines and free uropods. Regarding the third larval stage, Gurney \& Lebour (1941) described it as having the rostrum shorter than the antennal scaphocerite with ten small dorsal teeth, the flagellum of the antennule long, the first and second pereopods chelate, and the uropods reaching the convex distal margin of a parallel-sided telson (Gurney \& Lebour, 1941). No intermediate stage was described between the second and the third zoea, but it was registered that the second zoea corresponds to a normal third zoeal stage of a caridean larvae (Gurney \& Lebour, 1941). Finally, some figures of a possible fourth zoeal stage and the description of the "Post-larval 1", which corresponds to nowadays decapodid stage, with the thorax still full of yolk, are presented (Gurney \& Lebour, 1941).

Gathering information on the biological traits for mesopelagic species is difficult, since their capture and live maintenance under laboratory conditions are problematic. However, larval development under laboratory conditions for morphological purposes can be a useful way to acquire knowledge on feeding traits and development patterns. Throughout the adult phase of the life-cycle, during the oogenesis the energy for partially or entirely food-independent larval development is stored as egg yolk, establishing the degree of lecithotrophy or planktotrophy (e.g. Anger, 2001). Therefore, full lecithotrophy and planktotrophy are extremes in a continuum: full lecithotrophy corresponds to high yolk stores that allow no feeding during the development of the larvae, and planktotrophy corresponds to larvae that need to feed during their development (e.g. Anger, 2001). 
70

71

72

73

74

75

76

77

78

79

80

81

82

83

84

85

86

87

88

89

90

91

92

93

94

95

96

97

98

99

100

101

102

103

104

105

106

107

The present work aims to describe the complete larval development of Systellaspis debilis from laboratory reared material, comparing it with the previous description available for the species, and, presenting information on the development pattern of the larvae. Also, we discuss the implications of the lecithotrophy and planktotrophy of the larvae on the ecology and evolution of the oplophorid shrimps.

\section{Materials \& Methods}

\section{Specimen collection and larval culture}

The ovigerous females of Systellaspis debilis were collected in two different research surveys carried out by Instituto Português do Mar e da Atmosfera, I.P. (IPMA, former IPIMAR) off the southwest and southern coasts of Portugal, in August 2010 and June 2011 onboard of RV Noruega, as a by-catch of the plankton sampling (Bongo net, with $90 \mathrm{~cm}$ of diameter aperture, and $500 \mu \mathrm{m}$ of mesh size) and the crustacean bottom trawls (field permit approval by IPMA, Oceanographic Survey MedEx- 02060810, and Nephrops Survey Offshore Portugal- 02030611, respectively). A total of thirteen ovigerous females were obtained in both years. All females were captured dead, each carrying between a minimum of two and a maximum of twelve eggs (Table 1) that were immediately and carefully removed from the pleopods and transferred to $200 \mathrm{ml}$ glass beakers with aerated autoclaved seawater. Following Company \& Sardà (1997), three stages of egg development were defined: the early stage (1), with intense colour and no other pigmentation visible; the middle stage (2), an egg with a more pale colour and with an embryo having a slight eye pigmentation; and the late stage (3), an egg almost without colour and with an embryo with the eye pigmentation well visible and developed. In stages 2 and 3, the heartbeat was checked in order to know if the embryo was alive. Once at the laboratory, the elliptical eggs were measured on the major and the minor axes, corresponding respectively to its length and width, under a binocular microscope with a micrometer lens. Once at the laboratory, the elliptical eggs were measured on the major and the minor axes, corresponding respectively to its length and width, under a binocular microscope with a micrometer lens. The eggs were kept in autoclaved seawater with a salinity of $35 \pm 1$, a temperature of $18 \pm 1{ }^{\circ} \mathrm{C}$, a photoperiod of $12 \mathrm{~h}$ light: $12 \mathrm{~h}$ dark, and weak aeration. The eggs were checked daily until hatching. Once hatched, the larvae were separated with the aid of a glass pipette and transferred to a $30 \mathrm{ml}$ glass beaker, to be individually reared with constant weak aeration. During rearing, the larvae were kept in exactly the same conditions. The water was changed daily, and the larvae checked for the evidence of molting (presence of exuviae in the bottom of the culture recipient). In experiments carried out in 2010, a high hatching efficiency Artemia sp. (250000 nauplii.g-1 of product) prepared following Sorgeloos, Dhert \& Candreva (2001), were provided daily at a density of 10 nauplii.ml ${ }^{-1}$. No decrease in the density of Artemia was verified, leading us to suppose that these were nonfeeding larvae. Since it was observed that the larval cycle was completed, the experience was repeated in 2011 without food. In both years, the experiments finished with the 
108 larvae reaching the decapodid and juvenile stages, which were fixed in $4 \%$ borax buffered

109

110

111

112

113

114

115

116

117

118

119

120

121

122

123

124

125

126

127

128

129

130

131

132

133

134

135

136

137

138

139

140

141

142

143

144

145

146

formaldehyde along with the exuviae for later morphological analysis.

\section{Larval drawings and measurements}

Drawings and measurements were made following the method described in detail by Bartilotti, Salabert \& dos Santos (2016). The long plumose setae on the exopods of maxillipeds, and on the pleopods and uropods were drawn truncated, and the setules from setae were omitted from drawings when necessary. The number of examined specimens per stage $(\mathrm{N})$ is referred in the description. Measurements taken were: total length (TL), corresponding to the distance from the tip of the rostrum to the posterior end of telson; carapace length (CL), measured from the tip of rostrum to the posterior margin of the carapace; and rostrum length (RL), corresponding to the distance from the tip of rostrum to the eye socket (except in zoea I where it was not measured). Ten specimens of first to third zoeal stages, seven specimens of fourth zoeal stage, and six specimens of decapodid stage were measured. The larval series has been deposited in IPMAInstituto Português do Mar e da Atmosfera, in Lisbon, Portugal (IPIMAR/O/Sd/01/2011).

\section{Results}

\section{Rearing the larvae of Systellaspis debilis}

Under laboratory conditions the larvae hatched with a high amount of bright red yolk, stored in the pereon and observed throughout all the development (Figure 1). Hatching occurred three to forty days after the collection of the eggs (Table 1). During the larval rearing, both zoea and decapodid, stood still, floating most of the time, and swimming only as a response to an external stimulus (e.g. tactile stimuli with an autoclaved glass pipette).

In 2010 rearing experiments, no feeding behavior was observed, and the larvae went through the entire larval cycle using their yolk. Therefore, no food was provided in the 2011 rearing experiments, but the decapodid stage was successfully achieved, after the 4 zoeal stages. Thus, we conclude that this species has a full lecithotrophic development. Considering the two years of experiments, with an average duration of $28.23 \pm 1.48$ days after hatching, the zoeae were able to molt and grow, going through the metamorphosis to the decapodid. The duration of the successive stages was 4- 6 days for stage I, 5- 8 days for stages II and III, 8- 11 days for stage IV. After 12 days, two of the decapodid stage larvae were able to molt, one in 2010 and another in 2011, reaching the first juvenile stage without food.

\section{Description of the complete larval development of Systellaspis debilis}

Under laboratory conditions at $18 \pm 1^{\circ} \mathrm{C}$ of temperature, four zoeal stages and one decapodid were identified, and are described in detail.

\section{Systellaspis debilis (A. Milne-Edwards, 1881)}

(Figures 2-7) 
147

148

149

150

151

152

153

154

155

156

157

158

159

160

161

162

163

164

165

166

167

168

169

170

171

172

173

174

175

176

177

178

179

180

181

182

183

184

185

186

First zoea

Dimensions: $\mathrm{TL}=9.35-10.01 \mathrm{~mm} ; \mathrm{CL}=3.19-3.52 \mathrm{~mm} ; \mathrm{N}=5$.

Carapace (Figs 2A, 2B, 2C): rostrum small, down turned; eyes compound and sessile; pterigostomian spine present, followed by $8-9$ very small denticles.

Antennule (Fig 2D): peduncle unsegmented, with 1 terminal plumose seta and short outer flagellum with 1 plumose seta and 2 shorter+ 1 longer aesthetascs terminally.

Antenna (Fig 2E, 2F): protopod unsegmented, with a small strong distal papposerrate seta; endopod less than half the length of the scaphocerite, apically with 1 plumose seta; scaphocerite unsegmented, broad, with 24- 26 plumose setae and 1 small spine on apex.

Mandibles (Fig 2G): slightly asymmetrical, with undifferentiated molar and incisive processes; palp present.

Maxillule (Fig 2H): coxal endite with 1- 2 small spines, basial endite with 1 small spine; endopod unsegmented with 1 short simple seta at half the length, 1 spine subterminally and 2 plumose setae terminally.

Maxilla (Fig 2I): coxal endite bilobed with 2 simple $+2-3$ plumose setae, basial endite bilobed with 1 simple and 1 plumose +2 simple and 1 plumose setae; endopod unsegmented bearing $2+1+1+3$ plumose setae; scaphognathite with 8- 10 marginal plumose setae, and one long distal stout setose process.

First maxilliped (Fig 2J): coxa with 2- 3 simple setae; basis with 7- 8 simple setae; endopod 4-segmented with 1, 1, 1+ 1, 1+ 3 plumose setae; exopod unsegmented, bearing 2 shorter plumose setae subterminally and 3 plumose setae terminally; epipod present.

Second maxilliped (Fig 2K): coxa with 1 simple seta; basis with 3- 4 simple setae; endopod 5-segmented with 2, 1, 0, 1 and 3 simple terminal setae; exopod unsegmented, bearing 2 subterminal and 3 terminal plumose setae; epipod present.

Third maxilliped (Fig 2L): coxa unarmed; basis with 2- 3 simple setae; endopod 5segmented with 1-2, 1, 0, 1- 2 and 3 simple setae; exopod unsegmented, bearing 2 subterminal and 3 terminal plumose setae.

First to fifth pereopods (Fig 2M): biramous buds, with pleurobranchs present; photophores present on the fifth pair of pereopods.

Pleon (Fig 2A, 2N): 5 pleomeres, without setae or spines, fifth pleomere with a rounded pleura.

Pleopods (Fig 2A, 2O): present as biramous buds; photophores present on first and second pleopods.

Uropods: absent.

Telson (Fig 2N, 2P): triangular, broader posteriorly, with a small median indent, with $7+7$ setae, the inner 5 plumose and the outer 2 plumose on proximal axis only.

Second zoea

Dimensions: $\mathrm{TL}=10.34-11.00 \mathrm{~mm} ; \mathrm{CL}=3.52-3.85 \mathrm{~mm} ; \mathrm{RL}=0.66-0.88 ; \mathrm{N}=5$. 
187

188

189

190

191

192

193

194

195

196

197

198

199

200

201

202

203

204

205

206

207

208

209

210

211

212

213

214

215

216

217

218

219

220

221

222

223

224

225

226

Carapace (Figs 3A, B): eyes stalked, with the ocular peduncle reaching half the length of the antennal peduncle; rostrum triangular, as long as the eyes; pterigostomian spine followed by 8- 9 small denticles.

Antennule (Fig 3C): peduncle 3-segmented, with 1 small spine positioned at about two thirds of the length of the first segment +3 plumose setae along the inner margin $+7-8$ plumose setae distributed on distal outer margin, second segment with 2 plumose setae along the inner margin $+5-6$ plumose setae distributed on distal outer margin, and distal segment with 1 plumose seta on inner margin +1 short plumose and 1 simple setae on outer margin $+6-7$ plumose setae distally; inner flagellum 2-segmented, first segment naked and distal segment bearing 1 simple seta distally; outer flagellum unsegmented with 2 aesthetascs at one third of the length of the segment +2 aesthetascs at two thirds of the length of the segment +1 simple seta terminally.

Antenna (Fig 3D): protopod unsegmented with a small strong simple spine; 2 -segmented endopod longer than half the length of the scaphocerite, shorter basal segment naked, terminal longer segment with 1 plumose seta distally; scaphocerite with 30- 31 plumose setae and 1 strong spine on apex.

Mandibles (Fig 3E): palp enlarged in size, otherwise unchanged.

Maxillule (Fig 3F, 3G, 3H): coxal endite with 1- 3 spines, basial endite with 1 spine; endopod unchanged.

Maxilla (Fig 3I): coxal endite bilobed with 2- 3 simple +1 spine and 2- 3 plumose setae distributed as illustrated; basial endite bilobed with 1 plumose seta and $1+1$ spines, 1 simple and 1 plumose setae; endopod unsegmented bearing $2+1+1+3$ plumose setae; scaphognathite with 10- 13 marginal plumose setae, and one long distal stout setose process.

First maxilliped (Fig 3J): coxa with 1 small spine and 1 plumose seta; basis with 2 small spines and 4-6 plumose setae distributed as illustrated; endopod 4-segmented with 1 plumose seta on inner margin and 1 plumose seta on outer margin, 1 plumose seta, 1 simple and 1 plumose setae, and 1+ 3 plumose setae; exopod unsegmented, bearing 2 shorter setae subterminally and 4 long terminal plumose setae; epipod unchanged.

Second maxilliped (Fig 3K): coxa with 1- 2 plumose setae; basis with 3- 4 plumose setae; endopod 5-segmented with 1, 1, 0, 0-1, and 1+3 plumose setae; exopod unsegmented bearing 2 shorter setae subterminally and 4 long terminal plumose setae; epipod unchanged.

Third maxilliped (Fig 3L): coxa unarmed; basis with 2- 3 plumose setae; endopod 5segmented with 1, 1, 0, 2, and 3 plumose setae; exopod unsegmented, bearing 2 subterminal and 4 terminal plumose setae.

First to fifth pereopods (Fig 3M): first pereopod endopod and exopod bearing one small simple seta apically, otherwise unchanged besides size.

Pleon (Fig 3A): unchanged besides size.

Pleopods (Fig 3A, N): biramous buds enlarged in size; photophores present on first to third pleopods.

Uropods: absent, but already visible under telson integument. 
227

228

229

230

231

232

233

234

235

236

237

238

239

240

241

242

243

244

245

246

247

248

249

250

251

252

253

254

255

256

257

258

259

260

261

262

263

264

265

266

Telson (Fig 3O): with a very small median indentation, now with $8+8$ setae, the inner 7 plumose and the outer plumose on proximal axis only.

\section{Third zoea}

Dimensions: $\mathrm{TL}=10.45-11.00 \mathrm{~mm} ; \mathrm{CL}=3.63-3.96 \mathrm{~mm} ; \mathrm{RL}=0.77-0.88 ; \mathrm{N}=6$.

Carapace (Figs 4A, 4B): pterigostomian spine followed by 8- 9 small denticles on lateral antero-ventral margin.

Antennule (Fig 4C): peduncle 3-segmented, basal segment with 1 spine positioned at half the length of the segment, 1- 2 plumose setae on inner margin, 1 small plumose seta on the stylocerite, and 9- 12 plumose setae distributed on distal outer margin; second segment with 2 plumose setae along the inner margin and 5- 7 plumose setae distributed on distal outer margin; distal segment with $2+2$ plumose setae along inner margin, 6 short plumose and 4 plumose setae on distal outer margin; inner flagellum 4-segmented, first and second segments naked, distal segment bearing 2 simple subterminal+ 1 plumose terminal setae; outer flagellum 4-segmented with 1, 3, and 3 aesthetascs in the first three segments, and $1+1$ simple setae terminally.

Antenna (Fig 4D): protopod unsegmented with a strong spine; 2-segmented endopod longer than three quarters of the length of the scaphocerite, shorter basal segment naked, terminal longer segment with 2- 3 very small simple setae terminally; scaphocerite with 32- 34 plumose setae and 1 strong spine on apex.

Mandibles (Fig 4E): palp enlarged in size, otherwise unchanged.

Maxillule (Fig 4F, 4G, 4H): coxal endite with 3 very small spines, basial endite with 4- 5 spines; 2-segmented endopod, proximal segment with 1 simple seta, distal segment with 1 spine subterminally and 2 plumose setae terminally.

Maxilla (Fig 4I): coxal endite bilobed with 3-4+ 3 simple and plumose setae distributed as illustrated, basial endite bilobed with 2-3+3- 4 simple and plumose setae; endopod unsegmented bearing $2+1+1+3$ plumose setae; scaphognathite with $15-17$ marginal plumose setae, microtricha as illustrated, and one long distal stout setose process.

First maxilliped (Fig 4J): coxa with 2 simple setae; basis with 7- 8 simple and plumose setae distributed as illustrated; endopod 4-segmented with 1+ 1 plumose setae on inner margin and 1 plumose seta on outer margin, 1 plumose seta, 1 simple and 1 plumose setae, and 1 shorter subterminal+ 3 longer terminal plumose setae; exopod unsegmented, bearing 2 shorter setae subapically and 4 long terminal plumose setae; epipod enlarged in size.

Second maxilliped (Fig 4K): coxa with 1- 2 plumose setae; basis with 4- 5 plumose setae; endopod 5-segmented with 2, 1, 0-1,1+1, and 1+2 plumose setae; exopod unsegmented bearing 2 shorter setae subapically and 4 long terminal plumose setae; epipod enlarged in size.

Third maxilliped (Fig 4L): coxa unarmed; basis with 3- 4 plumose setae; endopod 5segmented with $1-2,1,0,1+1$, and 3 plumose setae; exopod unsegmented, bearing 2 subterminal and 4 terminal plumose setae.

First to fifth pereopods (Fig 4M): first pereopod endopod 5-segmented, subchelate, with internal distal margin of propodus produced forward to about one-third of dactylus, with $1+1$ 
267

268

269

270

271

272

273

274

275

276

277

278

279

280

281

282

283

284

285

286

287

288

289

290

291

292

293

294

295

296

297

298

299

300

301

302

303

304

305

306

simple setae distally on terminal segment, and exopod unsegmented bearing 2 simple setae apically; second to fifth pereopods endopod 5-segmeted bearing 1 - 2 very small simple setae terminally, and exopod unsegmented with 1- 2 very small simple setae terminally; photophores present on the fifth pair of pereopods.

Pleon (Fig 4A): first to fifth pleomeres unchanged; sixth pleomere separated from the telson with 6 pairs of small simple setae distributed as figured.

Pleopods (Fig 4A, 4N, 4O, 4P, 4Q, 4R, 4S): enlarged in size; first pleopod endopod rudimentary, bud-like, and exopod with 1 small spine subterminally and 2 small spines terminally; second to fifth pleopods endopod rudimentary, bud-like, and exopod with 2 small spines terminally. Photophores present on first to fourth pleopods.

Uropods (Fig 4A, 4T, 4U, 4V): biramous; endopod small with 2- 3 short plumose seate apically; exopod well developed shorter than the posterior margin of telson, with 12- 14 marginal plumose setae and 2- 3 plumose setae on ventral margin.

Telson (Fig 4A, 4T): separated from the sixth pleomere, with $8+8$ setae.

\section{Fourth zoea}

Dimensions: $\mathrm{TL}=10.80-11.28 \mathrm{~mm} ; \mathrm{CL}=3.84-4.00 \mathrm{~mm} ; \mathrm{RL}=0.80-1.04 ; \mathrm{N}=4$.

Carapace (Figs 5A, 5B): three luminous organs on eye; rostrum extending beyond the eyes, with 9- 10 dorsal teeth and 2 very small ventral teeth; pterigostomian spine followed by 7 9 very small spines on lateral ventral margin.

Antennule (Fig 5C): peduncle 3-segmented, basal segment with 1 spine positioned at two thirds of the length of the segment, 2- 3 plumose setae on inner margin, 2 small plumose setae on the stylocerite, and 11- 13 plumose setae distributed on distal outer margin; second segment with 2- 3 plumose setae along the inner margin and 6- 7 plumose setae distributed on distal outer margin; distal segment with 8 subterminal plumose +6 terminal plumose setae distributed as illustrated; inner flagellum 6-segmented, first to third segments naked, third and fourth segments with 2- 3 simple setae, and terminal segment with 3- 4 simple setae; outer flagellum 5-segmented respectively with 1 aesthetasc, $2+3$ aesthetascs, 3 aesthetascs, 1 simple seta, and 2- 3 simple setae.

Antenna (Fig 5D): protopod unsegmented with one strong simple seta on the inner margin and one strong spine on the outer margin; endopod measuring almost one and a half times the length of the scaphocerite, with 18 segments each bearing 0 - 4 very small simple setae terminally; scaphocerite now with 35- 36 plumose setae and 1 strong spine on apex.

Mandibles (Fig 5E): incisor and molar processes as illustrated; palp enlarged in size, unsegmented.

Maxillule (Fig 5F): coxal endite with 6- 7 spines, basial endite with 7- 8 spines; 2segmented endopod, proximal segment with 1 simple seta, distal segment with 1 spine subterminally and 2 plumose setae terminally.

Maxilla (Fig 5G): coxal endite bilobed with 5-6+3 simple and plumose setae distributed as illustrated; basial endite bilobed with 3-4+3-4 simple and plumose setae; endopod 
307

308

309

310

311

312

313

314

315

316

317

318

319

320

321

322

323

324

325

326

327

328

329

330

331

332

333

334

335

336

337

338

339

340

341

342

343

344

345

346

unsegmented bearing $2+1+1+3$ plumose setae; scaphognathite with 17- 20 marginal plumose setae, and two distal stout setose processes.

First maxilliped (Fig 5H): coxa with 2 simple setae; basis with 8- 9 simple and plumose setae distributed as illustrated; endopod 4-segmented with $1+1$ plumose setae, $1+1$ plumose setae, $1+1$ plumose setae, and 1 shorter subterminal +3 longer terminal plumose setae; exopod unsegmented, bearing 2 shorter setae subapically and 4 long terminal plumose setae; epipod enlarged in size.

Second maxilliped (Fig 5I): coxa with 1- 2 plumose setae; basis with 5- 6 plumose setae; endopod 5-segmented with 2, 1, 0- 1, 2, and 1+ 2 plumose setae; exopod unsegmented bearing 2 shorter setae subapically and 4 long terminal plumose setae; epipod enlarged in size.

Third maxilliped (Fig 5J): coxa unarmed; basis with 3- 4 plumose setae; endopod 5segmented with $1-2,1,0,2$, and 3 plumose setae, and a luminous organ on the $4^{\text {th }}$ segment (propodus); exopod unsegmented, bearing 2 subterminal and 4 terminal plumose setae.

First pereopod (Fig 5K): functional, coxa unarmed; basis with 3 simple setae; endopod subchelate, 5-segmented, ischium, merus and carpus with 1,1-2,1 simple setae respectively, as illustrated; distal margin of the propodus produced forward to about one-third of dactylus bearing 1- 2 simple setae +1 spinous process, dactylus with 1 simple seta +1 spinous process; exopod unsegmented, bearing 2 subterminal and 4 terminal plumose setae; pleurobranch developed.

Second pereopod (Fig 5L): functional, coxa unarmed; basis with 1 simple seta; endopod subchelate, 5-segmented, ischium, merus and carpus with 1, 1- 2, and 0 simple setae respectively, distal margin of the propodus produced forward to about one-third of dactylus bearing 1 simple seta +1 spinous process, dactylus with 1 simple seta +1 spinous process; exopod unsegmented, bearing 2 subterminal and 4 terminal plumose setae; pleurobranch developed.

Third pereopod (Fig 5M): functional, coxa unarmed; basis with 1 simple seta; endopod 5segmented, ischium, merus, carpus and propodus with 1, 0-1, 1, 2 simple setae, dactylus with 1 simple seta +1 spinous process; a luminous organ on the carpus; exopod unsegmented, bearing 2 subterminal and 4 terminal plumose setae; pleurobranch developed.

Fourth pereopod (Fig 5N): functional, coxa unarmed; basis with 1 simple seta; endopod 5-segmented, ischium, merus, carpus and propodus with $0-1,1,1,2$ simple setae, dactylus with 1 simple seta +1 spinous process; a luminous organ on the carpus; exopod unsegmented, bearing 4 terminal plumose setae; pleurobranch developed.

Fifth pereopod (Fig 5O): functional, coxa unarmed; basis naked; endopod 5-segmented, ischium, merus, carpus and propodus with 0,0,0,1 simple seta, dactylus ending in a spinous process; a luminous organ on the carpus; exopod unsegmented, bearing 2 small terminal simple setae; pleurobranch developed.

Pleon (Fig 5A, 5P, 5Q, 5R): first to third pleomeres unchanged; fourth pleomere with a posteromedial spine; fifth pleomere with a posteromedial spine and a spine on the pleura; sixth pleomere with a pair of lateral spines. 
347

348

349

350

351

352

353

354

355

356

357

358

359

360

361

362

363

364

365

366

367

368

369

370

371

372

373

374

375

376

377

378

379

380

381

382

383

384

385

386

Pleopods (Fig 5A, 5S): protopod naked; first pleopod endopod naked and exopod with 2 small spines; second to fiffth pleopods endopods and exopods with 2 small spines distally, appendix interna as bud, present from second to fifth pleopods. Photophores present on first to fifth pleopods.

Uropods (Fig 5T): protopod without setae; endopod with 2- 3 short plumose setae medially on outer margin and 14- 16 plumose setae along distal and inner margins; exopod, with 1 small spine on apex followed by 20- 22 plumose setae along distal and inner margin, and 2- 3 plumose setae on ventral margin.

Telson (Fig 5T): with a median spine on posterior margin, followed by 5 pairs of strong plumose processes on the posterior end being the fourth pair plumose only on the inner margin, 2 pairs of outer spines, and 1 pair of lateral spines; almost rectangular shaped.

\section{Decapodid}

Dimensions: $\mathrm{TL}=11.77-12.10 \mathrm{~mm} ; \mathrm{CL}=4.40-4.62 \mathrm{~mm} ; \mathrm{RL}=1.10-1.32 ; \mathrm{N}=4$.

Carapace (Fig 1, 6A, 6B, 6C): eyestalk with ocellus on medio-distal portion, and three luminous organs; rostrum shorter than scaphocerite with 9- 10 dorsal teeth and 2- 3 small ventral teeth; antennal spine present, and pterigostomian spine followed by 10- 11 small spines on lateral ventral margin.

Antennule (Fig 6H): peduncle 3-segmented, basal segment with 1 spine positioned at two thirds of the length of the segment, 3- 5 plumose setae on inner margin, 1- 2 small plumose setae on the stylocerite, and 11- 13 plumose setae distributed on distal outer margin; second segment with 2- 3 plumose setae along the inner margin and 6- 8 plumose setae distributed on distal outer margin; distal segment with 7-9 subterminal plumose $+7-8$ terminal plumose setae distributed as illustrated; inner flagellum 10- 11 segments each with 0- 5 simple setae; outer flagellum 1011 segments, first three segments with 1 aesthetasc, $2+3$ aesthetascs +1 simple seta, and $3+3$ aesthetascs, fourth to last segment naked to 3 simple setae distally.

Antenna (Fig 6I): protopod 2-segmented, distal segment with one simple seta and one strong spine; endopod longer than the scaphocerite, with 33- 36 segments each bearing 0 - 5 very small simple setae terminally; scaphocerite now with 39- 41 plumose setae, 1 strong spine on apex, and 1- 2 simple setae distributed along outer margin.

Mandibles (Fig 6J): palp 2-segmented, proximal segment with 2 plumose setae, distal segment with 2 simple +4 plumose setae; incisor process with about ten to 12 strong serrated teeth, molar process as illustrated.

Maxillule (Fig 6K): coxa with 10- 12 simple and papposerrate setae; basis with 15- 17 cuspidate and papposerrate setae; 2 -segmented endopod, proximal segment with 1 longer subterminal and 1 shorter terminal outer plumose setae, distal segment with 2 plumose setae terminally.

Maxilla (Fig 6L): coxal endite bilobed with 6- 7+ 3 setae; basial endite bilobed with 5- 6+ 6- 7 setae; endopod unsegmented bearing $1+1+1$ and 3 plumose setae terminally; scaphognathite with 21-23 marginal plumose setae. 
First maxilliped (Fig 6M): coxa with 3- 4 setae; basis with 12- 13 papposerrate setae; endopod 3-segmented, with 1+1, 1, 1+ 3 papposerrate setae distributed as figured; exopod with 9- 10 short plumose setae on outer margin, 3 terminal plumose setae and 1 shorter plumose seta subapically on inner margin; epipod bilobed.

Second maxilliped (Fig 6N): coxa with 1 plumose seta; basis with 5- 7 plumose setae; endopod 5-segmented with 1-2+1, 1+ 1, 0- 1, 6- 7, and 10- 11 plumose setae; exopod unsegmented bearing 2 setae subapically and 4 long terminal plumose setae; epipod enlarged in size.

Third maxilliped (Fig 6O, 6P): coxa unarmed; basis with 3- 4 plumose setae; endopod 5segmented with 4- 5 plumose setae, 1 spine +6 - 7 plumose setae, 5 - 6 plumose setae, 8- 10 plumose setae, and 2 spines +2 simple setae distributed as illustrated, and a luminous organ on the $4^{\text {th }}$ segment (propodus); exopod unsegmented, bearing 2 subterminal and 4 terminal plumose setae.

First pereopod (Fig 7A, 7B): coxa naked, basis with 3- 5 plumose setae; endopod subchelate, 5-segmented, ischium, merus and carpus with 8- 9, 4- 5 and 2- 4 simple and plumose setae distributed as illustrated, propodus produced beyond half the length of the dactylus bearing 5- 7+ 4- 6 simple setae distributed as illustrated and 2 spines distally, dactylus with 2- 4 simple setae and 2 spines distally; exopod unsegmented, bearing 2 subterminal and 4 terminal plumose setae; pleurobranch developed.

Second pereopod (Fig 7C, 7D): coxa naked, basis with 2- 3 plumose setae; endopod subchelate, 5-segmented, ischium, merus and carpus with 4- 6, 4- 5 and 3- 4 simple and plumose setae distributed as illustrated, propodus produced half the length of the dactylus bearing 4- 5+ 32 simple setae distributed as illustrated and 2 spines distally; dactylus with 3- 5 simple setae and 2 spines distally; exopod unsegmented, bearing 2 subterminal and 4 terminal plumose setae; pleurobranch developed.

Third pereopod (Fig 7E, 7F): coxa naked; basis with 1- 2 plumose setae; ischium, merus, carpus and propodus with 1-3, 3-4, 2- 3 and 4- 5 simple and plumose setae arranged as figured, luminous organ present on carpus; dactylus with 3- 5 simple setae and 2 spines distally; exopod unsegmented, bearing 2 subterminal and 4 terminal plumose setae; pleurobranch developed.

Fourth pereopod (Fig 7G): coxa naked; basis with 2 plumose setae; ischium, merus, carpus and propodus with 2-3,1-2, 2- 3 and 5- 6 simple and plumose setae arranged as figured, luminous organ present on carpus; dactylus with 3- 4 simple setae and 1 spine distally; exopod unsegmented, bearing 2 subterminal and 4 terminal plumose setae; pleurobranch developed.

Fifth pereopod (Fig 7H, 7I): coxa naked; basis with 1- 2 plumose setae; ischium, merus and carpus with 1-2,1-2 and 4- 5 simple and plumose setae arranged as figured; propodus with 1 stout plumose seta at two thirds of the length of the segment and 5- 6 plumose and simple setae distributed, luminous organ present on carpus; dactylus with 1- 2 simple setae subterminally and 4 stout simple setae distally; exopod short, measuring less than one third of the length of the endopod, bearing 4 terminal plumose setae; pleurobranch developed. 
426

427

428

429

430

431

432

433

434

435

436

437

438

439

440

441

442

443

444

445

446

447

448

449

450

451

452

453

454

455

456

457

458

459

460

461

462

463

464

465

Pleon (Figs 1, 6A, 6D, 6E, 6F, 6G): third to fifth pleomeres with a posteromedial spine, being the one on somite 3 strong, the one on somite 4 slightly upturned, and the one on somite 5 which also bears a lateral spine, acute; sixth pleomere with a pair of lateral spines. Photophores present on the base of each pair of pleopods, close to their insertion in the pleon.

First pleopod (Fig 6A, 7J, 7K): basipodite naked; endopod with 2 subterminal plumose setae and 2 cincinulli, exopod with 15- 16 plumose setae

Second pleopod (Fig 6A, 7L, 7M): basipodite smooth; endopod with 10- 11 plumose setae and the small appendix interna which presents 2 cincinulli, exopod with 16- 17 plumose setae.

Third pleopod (Fig 6A, 7N, 7O): basipodite smooth; endopod with 10 plumose setae and the small appendix interna which presents 2 cincinulli; exopod with 14- 15 plumose setae.

Fourth pleopod (Fig 6A, 7P, 7Q): basipodite smooth; endopod with 9- 10 plumose setae and the small appendix interna which presents 2 cincinulli; exopod with 14- 15 plumose setae.

Fifth pleopod (Fig 6A, 7R, 7S): basipodite smooth; endopod with 8- 9 and the small appendix interna which presents 2 cincinulli; exopod with 13- 14 plumose setae.

Uropods (Fig 7T): protopod unarmed; endopod with 19- 20 plumose setae along inner and distal margins, 4- 5 sparsely plumose setae along outer margin and 2- 5 sparsely plumose setae distributed on ventral margin; exopod with 24- 25 plumose setae along inner and distal margins, 2- 3 sparsely plumose setae along outer margin and 2- 4 sparsely plumose setae distributed on ventral margin.

Telson (Fig 7T): parallel-sided, presents a slightly convex distal margin with a short median spine, 2 pairs of small lateral spines and 6 pairs of processes distally (the first pair is the shortest, the second pair the longest, and the second to the sixth are plumose); small anal spine now present.

\section{Discussion}

\section{Morphology of the larval cycle of Systellaspis debilis and larval characters for the Oplophoridae}

The complete larval development of Systellapis debilis described in present study has four zoeae and one decapodid, which adds a zoea to the, until now known larval sequence for this species. The Gurney \& Lebour (1941) description, based on a sequence of larval stages from plankton of Bermuda waters, presents a larval cycle of three zoea and a post-larval stage (=decapodid). However, Gurney \& Lebour (1941) indicate that the second zoeal stage has a telson with $8+8$ posterior processes and free uropods, whereas the results from this study shows that the uropods are visible through the telson integument but not free. In fact, Gurney \& Lebour had concluded that the second zoea corresponded to a normal third stage (Gurney \& Lebour, 1941).

Nonetheless, after a detailed morphological comparison between present work and Gurney \& Lebour (1941) S. debilis larval descriptions, we found only minor differences, which concerns the setation of some appendages and the dimensions of the larvae. When comparing the first zoea, the maxilla previously described lacks detail in the coxal and basial lobes with $2+0$ and 
$4661+1$ small setae, which are ornamented with $2+2-3$ and $2+3$ setae in the coxa and basis, 467 respectively. The telson is described as having the uropods under its integument, which in the 468 present work are visible only in the second zoeal stage.

469 The second zoea described in present study was not previously observed by Gurney \& 470 Lebour (1941). For the third zoeal stage, the only difference between the two descriptions is in 471 the number of setae of the scaphognathite of the maxilla that presents 15-17 marginal plumose 472 setae and 1 long distal stout setose process, instead of 13 marginal plumose processes as in 473 Gurney \& Lebour (1941) description. The fourth zoeal stage now presented slightly differs from

474

475

476

477

478

479

480

481

482

483

484

485

486

487

488

489

490

491

492

493

494

495

496

497

498

499

500

501

502

503

504 the Gurney \& Lebour (1941) third stage, by the presence of two very small ventral teeth in the rostrum, and the more setae found in the maxillule and in the maxilla. Gurney \& Lebour also compare the third larval stage with a specimen taken at Bermuda (Gurney \& Lebour, 1941), considering that probably it is a fourth stage. Comparing this specimen with the fourth zoeal stage obtained in present study, we conclude that it differs in the flagellum of the antenna, which is longer than the exopod, and in the telson that is slightly wider at the posterior end, with a straight posterior margin (Gurney \& Lebour, 1941).

We agree with Gurney \& Lebour (1941) probable explanation for the observations made that there is some variation in the number of stages after the second zoea, also because the characters of the telson agree well with those described in present study for the fourth zoeal stage. Besides this, Gurney \& Lebour describe another probable larval stage four, collected in the Discovery station 281 (see Fig 6A-C in Gurney \& Lebour, 1941), different from the one described in the present study for the decapodid stage. Gurney \& Lebour (1941) stage four presents 6 ventral teeth in the rostrum, the carapace has an anterior ventral margin slightly serrated, the maxillule, maxilla and first maxilliped are figured, and the telson is described as more slender, presenting a long median spine. The author then compares this larval form with the one described in Kemp (1907), hypothesizing that both correspond to the same stage, possibly of a different species or of an intermediate stage between the last zoeal stage and the first decapodid. When compared with the fourth zoea described by us, they differ in the number of ventral teeth of the rostrum and in the form of the telson, which in the present study is rectangular shaped with a median spine with the same size of the other telson posterior process. Regarding the endopod of the maxillule of the specimen collected in the Discovery station 281 (Gurney \& Lebour, 1941), it seems unsegmented, which is segmented in the fourth zoea described here; also, the endopod of the maxilla possess only 3 setae which in the present description has $2+1+1+3$ plumose setae. The larvae described by Gurney \& Lebour (1941) presents a first maxilliped similar to the one observed for a decapodid stage, with a 3-segmented endopod, the exopod with plumose setae along the outer margin, and, the epipod bilobed, whereas the fourth zoea described here presents a first maxilliped typical of a zoeal stage, with a 4-segmented endopod, the exopod with plumose setae terminally, and, a small epipod. Therefore, since the Discovery station 281 larvae described by Gurney \& Lebour (1941) has a telson and the first maxilliped similar to those of the decapodid stage, and the endopods of both, the maxillule 
505 and maxilla, are different in shape and number of setae, we consider that, probably, it belongs to 506 a different Oplophorid species.

507

508

509

510

511

512

513

514

515

516

517

518

519

520

521

522

523

524

525

526

527

528

529

530

531

532

533

534

535

536

537

538

539

540

541

542

543

It is recognized that the number of stages can be a consequence of the genetic differences between regionally separated populations (e.g. Anger, 2001), of the energy content of larvae at hatching as a proxy for the Per Offspring Investment (POI, e.g. Oliphant \& Thatje, 2013), or of the environmental conditions such as the temperature (e.g. Oliphant, Hauton \& Thatje, 2013). The plasticity in the number of larval stages is common for shrimps, and results published to date show that temperature, salinity and food affect the moult cycle, and can produce intermediate forms (e.g. different morphs of Nauticaris magellanica from the third zoeal stage on, as described in Wehrtmann \& Albornoz, 2003). Likewise, besides the morphological plasticity, different populations of the same species can have larval cycles with a different number of stages (e.g. populations of N. magellanica from the Argentine waters- Atlantic ocean- and the Chilean waters- Pacific ocean- differed in the number of stages, size, setation of thoracopods, and development of pereopods, as described in Thatje \& Barcadirt, 2000). Back to 1941, Gurney and Lebour (1941) were already aware of this, indicating that the differences observed between the Bermuda and the Discovery specimens might be due to the individual variation in the degree of development between the two populations. This plasticity is more common for long larval series than for short ones(e.g. Anger, 2001), where the critical periods related with quantity and quality of energy affect the moult cycle (e.g. Wehrtmann \& Albornoz, 2003). The larval cycle of Systellaspis debilis has been shown here to be fully lecitorophic, and possibly less variation is expected for this group of species, since the changes in the energy requirements throughout development are already provided for in the strongly enhanced yolk stores.

Gurney's decapodid, described as "post-larval 1" (Gurney \& Lebour, 1941) is smaller in size when compared with those obtained in present study, but shows a longer rostrum with 13 dorsal teeth and 8 small ventral teeth and, the telson illustrated seems to be more developed. On the other hand, Coutiére (1906) presented a larval form that can be considered as a decapodid stage, having a total length of $11 \mathrm{~mm}$ (see Fig 2A, in Coutiére, 1906), the rostrum shorter than the scaphocerite, with the same number of dorsal teeth and a smaller number of ventral teeth (13 and 3 respectively). The distribution of the luminous organs and of the photophores is in agreement in all three descriptions. Both authors (Coutiére, 1906; and Gurney \& Lebour, 1941) mention that the pereon is full of yolk, as observed in the present study.

Gurney \& Lebour (1941) stated that the morphological larval characters for Systellaspis and Oplophorus are very similar, reflecting a closer relation between both genera. Besides the presence of the luminous organs, the two larval series differ on the antennal scaphocerite which in Oplophorus spinosus has a stout apical spine from first stage on, a small exopod on pereopod 5 , and a reduced ocular pappila. It is also stated, that probably the mouthparts remain not functional due to the mass of yolk observed in the body (Gurney \& Lebour, 1941), an assumption in agreement with our observations. Considering present knowledge, we conclude that species of the family Oplophoridae will, most probably, have a larval cycle of four to five

Peer) reviewing PDF | (2018:10:32096:2:1:NEW 14 Jun 2019) 
544 zoeae. The first zoea will have the exopod of the antenna unsegmented, will present buds for all 545 pereopods and pleopods, which will be biramous in all pereopods, the pereon will be full of yolk 546 through all larval development. The telson is broad presenting a small median spine on posterior 547 margin, in the last stage of zoea.

548

549

550

551

552

553

554

555

556

557

558

559

560

561

562

563

564

565

566

567

568

569

570

571

572

573

\section{Lecithotrophy in Systellaspis debilis larvae and its implications on the ecology and evolution} of oplophorids

We propose that the larval phase of S. debilis is full lecithotrophic, due to the findings within this study showing that the complete larval development, from the first zoea to decapodid, and first juvenile stage, occurred without feeding. Full lecithotrophy has been described as a probable evolutionary consequence of living in a habitat with ecological and physiological constraints (e.g. Anger, 2001), similar to the one where this species lives. This is mostly known for decapods inhabiting extreme habitats such as land locked species (e.g. Benzie, 1982 for Caridina mccullochi; Couret \& Wong, 1978 for Halocaridina rubra; and Rodriguez \& Cuesta, 2011 for Dugastella valentina, three atyid shrimps respectively with five, four, and two non feeding zoeal stages; and González-Gordillo, Anger \& Schubart, 2010 for Sesarma windsor and Metopaulias depressus, two sesarmid crabs with two non feeding zoeal stages). For species living in extreme habitats the evolutionary selection pressures are related with scarcity of food, temperature variation, and high salinity gradients. In some cases subsequent to the full lecithotrophy in one or more larval stages, facultative lecithotrophy is possible due to the quantity of yolk still stored in the pereon (e.g. Anger, 2001). A clear example of this pattern was described for a freshwater atyid with abbreviated development and parental care, Dugastella valentina (Crustacea, Decapoda, Caridea), whose first, second and third juvenile stages are facultative lecithotrophs (Rodriguez \& Cuesta, 2011). Observing the pereon of the juvenile stage of S. debilis, is possible to state that it is full of yolk, leading to the supposition that maybe, similarly to what was previously observed in the obligate lecithotroph $D$. valentina, also $S$. debilis juveniles could be facultative lecithotrophs (Rodríguez \& Cuesta, 2011).

Gurney \& Lebour (1941) separated the oplophorids in two distinct groups according to the size of the eggs: the large eggs genera Ephyrina, Hymenodora, Oplophorus and Systellaspis, versus the small eggs genera Acanthephyra and Notostomus. The authors related the size of the

574

575 eggs with the number of zoeal stages in the larval cycle predicting that species with small eggs would have a long larval cycle, and the ones with large eggs will have a short larval cycle of no

576

577 more than five zoeal stages (Gurney \& Lebour, 1941). The females of S. debilis observed in the

578 present study carried between 2 to 12 very large eggs (Table 1), supporting that prediction.

579 Consequently, knowing that the species Hymenodora glacialis and Oplophorus spinosus besides

580

581 the size of the eggs shared other characteristics such as the presence of pereopods and pleopods from the first zoeal stage (Gurney \& Lebour, 1941), we hypothesize that most probably these species will have a fully lecithotrophic larval development as well. 
584

585

586

587

588

589

590

591

592

593

594

595

596

597

598

599

600

601

602

603

604

605

606

607

608

609

610

611

612

613

614

615

616

617

618

619

620

621

622

623

extended parental care or enhanced female energy investment in a reduced number of offspring, occur at depths of $200 \mathrm{~m}$ or more. Contrasting with these, the species of the genus Acanthephyra, produce large numbers of larvae (r-strategists, investing in a high number of eggs), are distributed at depths of $200 \mathrm{~m}$ or upper. In fact, the larvae of S. debilis are rare in the plankton of the euphotic zone (up to $200 \mathrm{~m}$ depth) as shown in e.g. Dos Santos (1999), Torres et al. (2014) and Pochelon et al. (2017). Therefore they probably inhabit in deeper layers of the water column, restricting their dispersion, skipping the need and search for food in an oligotrophic environment such as the mesopelagic zone. This might be a strategy acquired to enhance the survival of the species, stabilizing the evolutionary trajectory imposed, and in accordance with the recent evidence of cryptic speciation in S. debilis (Atlantic vs. Pacific and Indian Oceans, as the recent results by Lunina, Kulagin \& Vereshchaka, 2018, seem to demonstrate).

Considering that the phylogenetic reconstructions are very effective for tracing character evolution and major life-history adaptations, a greatly reduced dependence of a vulnerable free living larva on planktonic food sources, is treated as a derived character, i.e. an advanced trait in evolution (e.g. Anger 2001), and an increase in maternal investment is considered a crucial step in the shift to non-feeding lecithotrophic development (e.g. Strathmann 1978). Considering the recent phylogenetic reconstructions, Bracken et al. (2009) suggested the polyphyly of the Oplophoridae, and Chan et al. (2010) recommended to consider the two families, Oplophoridae and Acanthephyridae. Later, Wong et al. (2015) phylogenetic analyses to trace the evolution of bioluminescence within the oplophorids, resulted in a two major clades topology, strongly supporting the monophyly of the first clade, the family Oplophoridae (Bayesian analysis- BAYposterior probabilities and Maximum Likelihood- ML- bootstrap values displayed of 100/100). The authors considered that the emergence of photophores, also occurred later in the evolution, and was restricted to the first clade. The lecithotrophy observed for the oplophorids seems to be similar to what has been stated for the sesarmid crabs (e.g. González-Gordillo, Anger \& Schubart, 2010), where the planktotrophy- lecithotrophy dichotomy appears to show the evolutionary radiation from the marine to the terrestrial environment, with the percentage of increased yolk storage, allowing respectively planktotrophy, facultative lecithotrophy or full lecithotrophy. Therefore, the oplophorid shrimps seem to be good candidates to study the evolutionary correlation between the two developmental pattern extremes in the mesopelagic environment: the planktotrophy in the larvae of the Acanthphyridae versus the full lecithotrophy of the Oplophoridae.

Enhanced yolk reserves constitute a strategy to reduce the nutritional vulnerability of the newly hatched larvae (e.g. Anger, 2001). Accordingly, considering a probable evolutionary trend towards a shortening of the planktotrophic larval phase (e.g. Strathmann, 1978), it is accepted that the tendency towards lecithotrophy is associated with a decrease in the number of larval stages (4- 5 zoeal stages; e.g. Anger, 2001). An abbreviated larval development similar to the one observed for $S$. debilis in the present study was already recorded for the larvae of Pasiphaea japonica (family Pasiphaeidae; Nanjo \& Konishi, 2009), hence both species hatch with the pereopods and pleopods as buds, and complete their larval cycle with four full lecithotrophic 
624 zoeal stages. But other developmental patterns are observed in the nature, describing different 625 evolutionary trajectories. Recently, Hernández-Ávila, Cambon-Bonavita \& Pradillon (2015), 626 while studying the larvae of the alvinocaridids, concluded that the observed undeveloped 627 mouthparts and the large amount of lipid reserves strongly support the occurrence of primary

628 lecithotrophy. Though, the alvinocaridids larvae undeveloped mouthparts are combined with the 629 lack of pereopods and pleopods, suggesting lecithotrophy only in the first zoea, a stage that can 630 last 70 days. The authors suppose that the combination of undeveloped mouthparts with the 631 absence of pereopods and pleopods in the newly hatched zoeae, suggests lecithotrophy, in an 632 extended larval development (with more that 4- 5 stages), defining a life history model consistent 633 with a wide dispersal strategy in the oligotrophic environment where these species live 634 (hydrothermal vents and/ or cold seeps).

635

\section{Conclusions}

637 Present work paramount the need for more larval descriptions of representatives of the superfamily Oplophoroidea, but also of other mesopelagic species, in order to elucidate the

639 general patterns of development in its two families, understanding the taxonomic significance of

640 different life history strategies and, clarifying the phylogeny of this group. The complete larval development of Systellapis debilis is described from laboratory reared material. The four zoeal and one decapodid stages were found to be full lecithotrophic. Considering the previous descriptions for the Oplophoridae, which larval cycle consists of four to five zoeae, we propose as larval characters for this family: the exopod of the antenna unsegmented from the first zoea, all pereopods and pleopods present as buds from the first zoea, exopods in all pereopods, the telson broad with a small median spine on posterior margin in the last zoeal stage, and the pereon full of yolk through all the larval development, suggesting a full lecithotrophic development. The full lecithotrophy pattern is a probable evolutionary consequence of living in the mesopelagic zone, and seems to be an ecological adaptation of this species to this extreme environment. Knowing that the larvae of $S$. debilis are rare in the plankton of the euphotic zone, they inhabit the deeper layers of the water column. Due to the yolk-based development, the larval survival is enhanced in the mesopelagic oligotrophic zone, as there is no search for food. Considering the phylogenetic analyses published to date and the observations made in present study, we consider that similarly to what has been stated for some land locked crabs, also the oplophorid shrimps, can be a good model to study the lecithotrophy vs planktothrophy extremes in the mesopelagic environment.

657

\section{Acknowledgements}

659

The specimens used in present study were collected and reared under appropriate permits and approved ethics guidelines. 


\section{References}

663 Anger K. 2001. The Biology of Decapod Crustacean Larvae. Crustacean Issues, 14: 1- 419

$664 \quad$ ISBN 9026518285.

665 Bartilotti C, Salabert J, Dos Santos A. 2016. Complete larval development of Thor amboinensis

666

667

668

(De Man, 1888) Decapoda: Thoridae) described from laboratory-reared material and

669 identified by DNA barcoding. Zootaxa, 4066: 399-420 DOI 10.11646/zootaxa.4066.4.3.

Benzie JAH. 1982. The complete larval development of Caridina mccullochi Roux, 1926

670

(Decapoda, Atyidae) reared in the laboratory. Journal of Crustacean Biology, 2: 493-513

671 DOI: $10.2307 / 1548091$.

Bracken H, Toon A, Felder DL, Martin JW, Finley M, Rasmussen J, Palero F, Crandall KA.

672 2009. The decapod tree of life: compiling the data and moving toward a consensus of

673

674 decapod evolution. Arthropod Systematics \& Phylogeny, 67 (1): 99-116.

675

676

677

678

679

680

681

682

683

684

685

686

687

688

Chan T-YLH, Lei HC, Li CP, Chu KH. 2010. Phylogenetic analysis using rDNA reveals polyphyly of Oplophoridae (Decapoda : Caridea). Invertebrate Systematics, 24 (2): $172-$ 181 DOI 10.1071/IS09049.

Company JB, Sardà F. 1997. Reproductive patterns and population characteristics in five deepwater pandalid shrimps in the Western Mediterranean along a depth gradient (150-1100 m). Marine Ecology progress Series, 148: 49-58 DOI 10.3354/meps148049.

Couret CL Jr, Wong DCL. 1978. Larval development of Halocaridina rubra Holthuis (Decapoda, Atyidae). Crustaceana, 34: 301-309.

Coutiére H. 1906. Note sur la synonymie et le devéloppement de quelques Hoplophoridae. Bulletin du Musée Océanographique de Monaco, 70: 1-20.

dos Santos A. 1999. Larvas de Crustáceos Decápodes ao Largo da Costa Portuguesa. PhD Thesis, University of Lisboa, Lisboa, Portugal.

Gaten E, Herring PJ (1995) Morphology of the reflecting superposition eyes of larval oplophorid shrimps. Journal of Morphology, 225: 19- 29 DOI 10.1002/jmor.1052250103.

689

690

691

692

693

694

695

696

697

698

699

700

701

González-Gordillo JI, Anger K, Schubart CD. 2010. Morphology of the larval and first juvenile stages of two Jamaican endemic crab species with abbreviated development, Sesatma windsor and Metopaulias depressus (Decapoda: Brachyura: Sesarmidae). Journal of Crustacean Biology, 30: 101- 121 DOI 10.1651/08-3110.1.

Gurney R, Lebour M. 1941. On the larvae of certain Crustacea Macrura, mainly from Bermuda. Journal of the Linnean Society of London, 41: 89-181.

Hernández-Ávila I, Cambon-Bonavita M-A, Pradillon F. 2015. Morphology of first zoeal stage of four genera of Alvinocaridid shrimps from hydrothermal vents and cold seeps: implications for ecology, larval biology and phylogeny. PLOS ONE, 10: e0144657 DOI 10.1371/journal.pone.0144657.

Kemp SW. 1907. Biscayan Plankton. Part XI. Decapoda. Transitions of the Linnean Society of London, 10: 205- 217.

Lunina AA, Kulagin DN, Vereshchaka AL. 2018. Oplophoridae (Decapoda: Crustacea): phylogeny, taxonomy and evolution studied by a combination of morphological and 
702

703

704

705

706

707

708

709

710

711

712

713

714

715

716

717

718

719

720

721

722

723

724

725

726

727

728

729

730

731

732

733

734

735

736

737

738

739

740

741

molecular methods. Zoological Journal of the Linnean Society, XX: 1-20 DOI 10.1093/zoolinnean/zly039.

Moran AL, McAlister JS. 2009. Egg size as a life history character of marine invertebrates: is it all it's cracked up to be? Biological Bulletin, 216: 226- 242 DOI 10.2307/25548157.

Nanjo N, Konishi K. 2009. Complete larval development of the Japanese glass shrimp Pasiphaea japonica Omori, 1976 (Decapoda: Pasiphaeidae) under laboratory conditions. Crustacean Research, 38: 77- 89 DOI 10.18353/crustacea.38.0_77.

Oliphant A, Thatje S. 2013. Per Offspring Investment implications for crustacean larval development: evolutionary insights into endotrophy and abbreviated development. Marine Ecology Progress Series, 493:207-217 DOI 10.3354/meps 10496.

Oliphant A, Hauton C, Thatje S. 2013. The implications of temperature-mediated plasticity in larval instar number for development within a marine invertebrate, the shrimp Palaemonetes varians. PLoS ONE, 8(9)e75785 DOI 10.1371/journal.pone.0075785.

Pochelon P, Pires R, Dubert J, Nolasco R, Santos AM, Queiroga H, Dos Santos A. 2017. Decapod larvae distribution and species composition off the southern Portuguese coast. Continental Shelf Research, 151: 53-61 DOI 10.1016/j.csr.2017.10.009.

Rodríguez A, Cuesta JA. 2011. Morphology of larval and first juvenile stages of the kangaroo shrimp Dugastella valentina (Crustacea, Decapoda, Caridea), a freshwater atyid with abbreviated development and parental care. Zootaxa, 2867: 43-58 DOI 10.11646/zootaxa.2867.1.3.

Sorgeloos P, Dhert P, Candreva P. 2001. Use of the brine shrimp, Artemia spp., in marine fish larviculture. Aquaculture, 200: 147-159 DOI 10.1016/S0044-8486(01)00698-6.

Strathmann RR. 1978. The evolution and loss of feeding larval stages of marine invertebrates. Evolution, 32 (4): 894-906 DOI 10.2307/2407502.

Thatje S, Bacardit R. 2000. Morphological variability in larval stages of Nauticaris magellanica (A. Milne Edwards, 1891) (Decapoda: Caridea: Hippolytidae) from South American waters. Bulletin of Marine Science, 66: 375-398.

Torres AP, dos Santos A, Balbín R, Alemany F, Massutí E, Reglero P (2014). Decapod crustacean larval communities in the Balearic Sea (western Mediterranean): Seasonal composition, horizontal and vertical distribution patterns. Journal of Marine Systems, 138: 112-126 DOI 10.1016/j.jmarsys.2013.11.017.

Wehrtmann I, Albornoz L. 2003. Larvae of Nauticaris magellanica (Decapoda: Caridea: Hippolytidae) reared in the laboratory differ morphologically from those in nature. Journal of the Marine Biological Association of the United Kingdom, 83: 949- 957 DOI 10.1017/S0025315403008130.

Wong JM, Pérez-Moreno JL, Chan T-Y, Frank TM, Bracken-Grissom HD. 2015. Phylogenetic and transcriptomic analyses reveal the evolution of bioluminescence and light detection in marine deep-sea shrimps of the family Oplophoridae (Crustacea: Decapoda). Molecular Phylogenetics and Evolution, 83: 278- 292 DOI 10.1016/j.ympev.2014.11.013. 


\section{Figures}

743 Figure 1-Systellaspis debilis, decapodid, yolk stored in the pereon.

744

745 Figure 2- Systellaspis debilis. First zoea: (A) total animal, lateral view. (B) detail of rostrum, 746 dorsal view. (C) detail of carapace anterior ventral margin. (D) antennule. (E) antenna. (F) detail

747 of antennal protopod seta. (G) mandibles. (H) maxillule. (I) maxilla. (J) first maxilliped. (K) 748 second maxilliped. (L) third maxilliped. (M) first to fifth pereopods. (N) pleopods. (O) pleon with 749 telson. (P) telson. Scale bars: $0.05 \mathrm{~mm}(\mathrm{~F}-\mathrm{G}) ; 0.1 \mathrm{~mm}$ (A- E, H- P).

750

751

752

753

754

755

756

757

758

759

760

761

762

763

764

765

766

767

768

769

770

771

772

773

774

775

776

777

778

779

780

781

Figure 3 - Systellaspis debilis. Second zoea: (A) total animal, lateral view. (B) detail of carapace anterior ventral margin. (C) antennule. (D) antenna. (E) mandibles. (F) maxillule. (G) detail of maxillule coxal endite. $(\mathrm{H})$ detail of maxillule basial endite. (I) maxilla. (J) first maxilliped. (K) second maxilliped. (L) third maxilliped. (M) first to fifth pereopods. (N) pleopods. (O) telson. Scale bars: $0.05 \mathrm{~mm}(\mathrm{G}-\mathrm{H}) ; 0.1 \mathrm{~mm}$ (A- F, I- L, O); $1 \mathrm{~mm}(\mathrm{M}-\mathrm{N})$.

Figure 4 - Systellaspis debilis. Third zoea: (A) total animal, lateral view. (B) detail of carapace anterior ventral margin. (C) antennule. (D) antenna. (E) mandibles. (F) maxillule. (G) detail of maxillule coxal endite. $(\mathrm{H})$ detail of maxillule basial endite. (I) maxilla. (J) first maxilliped. (K) second maxilliped. (L) third maxilliped. (M) first to fifth pereopods. (N) pleopods. (O) detail of first pleopod exopod posterior margin. (P) detail of second pleopod exopod posterior margin. (Q) detail of third pleopod exopod posterior margin. (R) detail of fourth pleopod exopod posterior margin. (S) detail of fifth pleopod exopod posterior margin. (T) telson and uropods. (U) detail of uropods. (V) detail of uropods endopod posterior margin. Scale bars: $0.05 \mathrm{~mm}$ (G- H, O- S, V); $0.1 \mathrm{~mm}(\mathrm{~A}-\mathrm{F}, \mathrm{I}-\mathrm{N}, \mathrm{T}-\mathrm{U})$.

Figure 5 - Systellaspis debilis. Fourth zoea: (A) total animal, lateral view. (B) detail of rostrum. (C) antennule. (D) antenna. (E) mandibles. (F) maxillule. (G) maxilla. (H) first maxilliped. (I) second maxilliped. $(\mathrm{J})$ detail of propodus posterior end and dactylus of third maxilliped. (K) first pereopod. (L) second pereopod. $(\mathrm{M})$ third pereopod. $(\mathrm{N})$ fourth pereopod. $(\mathrm{O})$ fifth pereopod. $(\mathrm{P})$ detail of fourth pleomere posteromedial margin. (Q) detail of fifth pleomere posterior margin. $(\mathrm{R})$ detail of sixth pleomere posterior margin. (S) pleopods. (T) telson and uropods. Scale bars: 0.1 $\mathrm{mm}(\mathrm{A}, \mathrm{C}-\mathrm{O}) ; 1 \mathrm{~mm}(\mathrm{~B}, \mathrm{P}-\mathrm{R}, \mathrm{S}-\mathrm{T})$..

Figure 6 - Systellaspis debilis. Decapodid: (A) total animal, lateral view. (B) detail of rostrum. (C) detail of carapace anterior ventral margin. (D) detail of third pleomere posteromedial margin. (E) detail of fourth pleomere posteromedial margin. (F) detail of fifth pleomere posterior margin. (G) detail of sixth pleomere posterior margin. (H) antennule. (I) antenna. (J) mandibles. (K) maxillule. (L) maxilla. (M) first maxilliped. (N) second maxilliped. (O) third maxilliped. (P) detail of propodus and dactylus of third maxilliped. Scale bars: $0.1 \mathrm{~mm}$ (A, D- P); $1 \mathrm{~mm}$ (B- C).

PeerJ reviewing PDF | (2018:10:32096:2:1:NEW 14 Jun 2019) 
782 Figure 7 -Systellaspis debilis. Decapodid: (A) first pereopod. (B) detail of propodus and dactylus 783 of first pereopod. (C) second pereopod. (D) detail of propodus and dactylus of second pereopod. 784 (E) third pereopod. (F) detail of propodus and dactylus of third pereopod. (G) fourth pereopod. (H) 785 fifth pereopod. (I) detail of propodus and dactylus of fifth pereopod. (J) first pleopod. (K) first 786 pleopod appendix interna posterior margin, detail of cincinulli. (L) second pleopod. (M) second 787 pleopod appendix interna posterior margin, detail of cincinulli. (N) third pleopod. (O) third 788 pleopod appendix interna posterior margin, detail of cincinulli. (P) fourth pleopod. (Q) fourth 789 pleopod appendix interna posterior margin, detail of cincinulli. (R) fifth pleopod. (S) fifth pleopod 790 appendix interna posterior margin, detail of cincinulli. (T) telson and uropods. Scale bars: 0.05 $791 \mathrm{~mm}(\mathrm{~K}, \mathrm{M}, \mathrm{O}, \mathrm{Q}, \mathrm{S}) ; 0.1 \mathrm{~mm}(\mathrm{~A}-\mathrm{J}, \mathrm{L}, \mathrm{N}, \mathrm{P}, \mathrm{R}, \mathrm{T})$. 


\section{Tables}

793 Table 1- Sampled females used in present study, per date of collection; number of eggs; stage of

794 the eggs- defined as early stage (1), with intense colour and no other pigmentation visible,

795 middle stage (2), with a more pale colour and an embryo having a slight eye pigmentation, and, 796 late stage (3), almost without colour and with an embryo with the eye pigmentation well visible 797 and developed (adapted from Company \& Sardà, 1997); size (length, corresponding to the major 798 axis distance $\mathrm{x}$ width, corresponding to the minor axis distance, in $\mathrm{mm}$ ) and volume of the eggs; 799 number of hatchings; and date of hatching. 


\section{Figure 1}

Decapodid, yolk stored in the pereon.

Systellaspis debilis, decapodid, yolk stored in the pereon.

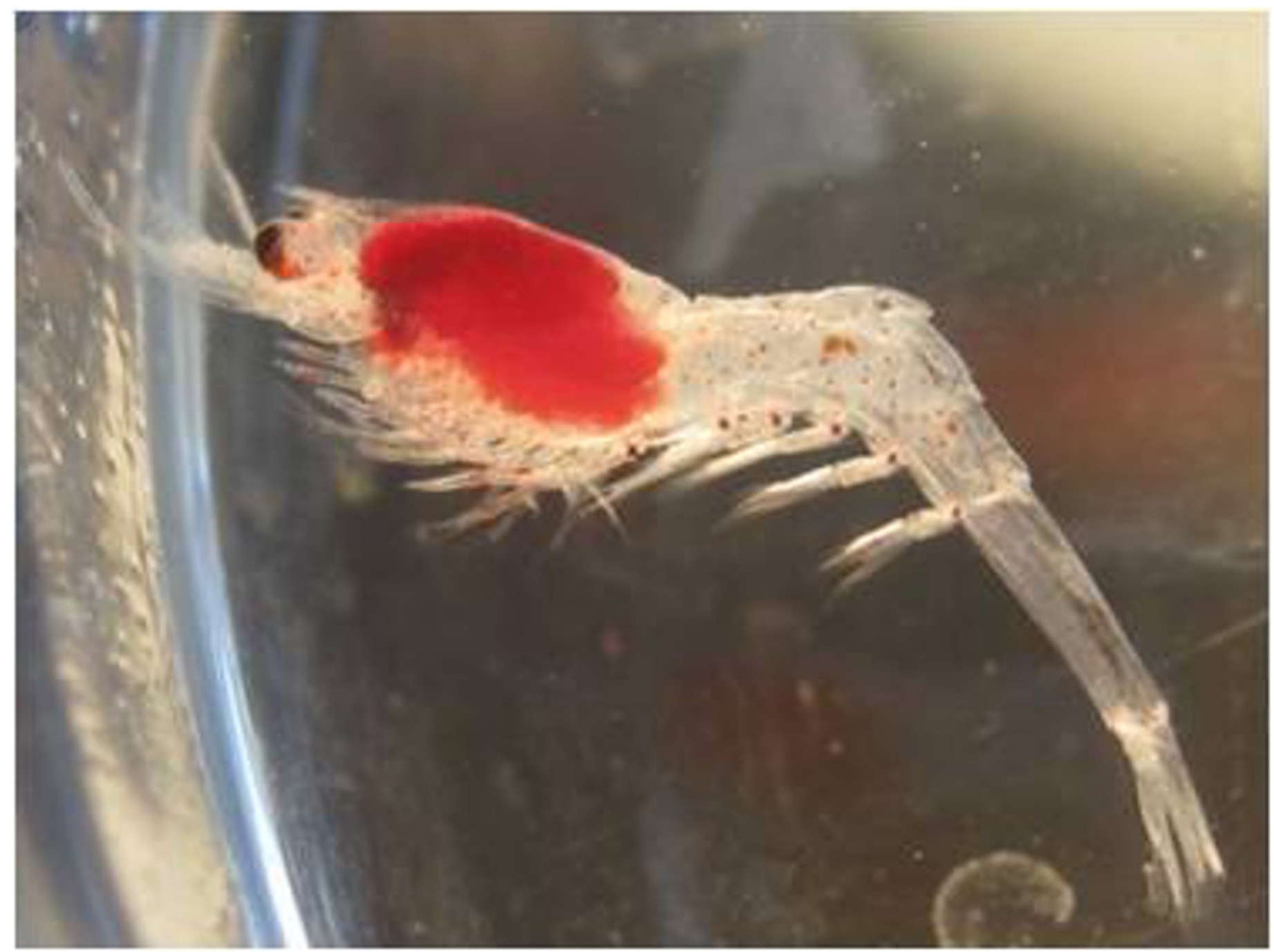




\section{Figure 2}

First zoea.

Systellaspis debilis . First zoea: ( $A$ ) total animal, lateral view . (B ) detail of rostrum, dorsal view . (C) detail of carapace anterior ventral margin . (D) antennule . (E) antenna . (F) detail of antennal protopod seta . (G) mandibles . (H) maxillule . (I) maxilla . (J) first maxilliped . (K) second maxilliped . (L) third maxilliped . (M) first to fifth pereo pods . (N) pleopods . (O) pleon with telson. $(P)$ telson. Scale bars: $0.05 \mathrm{~mm}(F-G) ; 0.1 \mathrm{~mm}(A-E, H-P)$. 


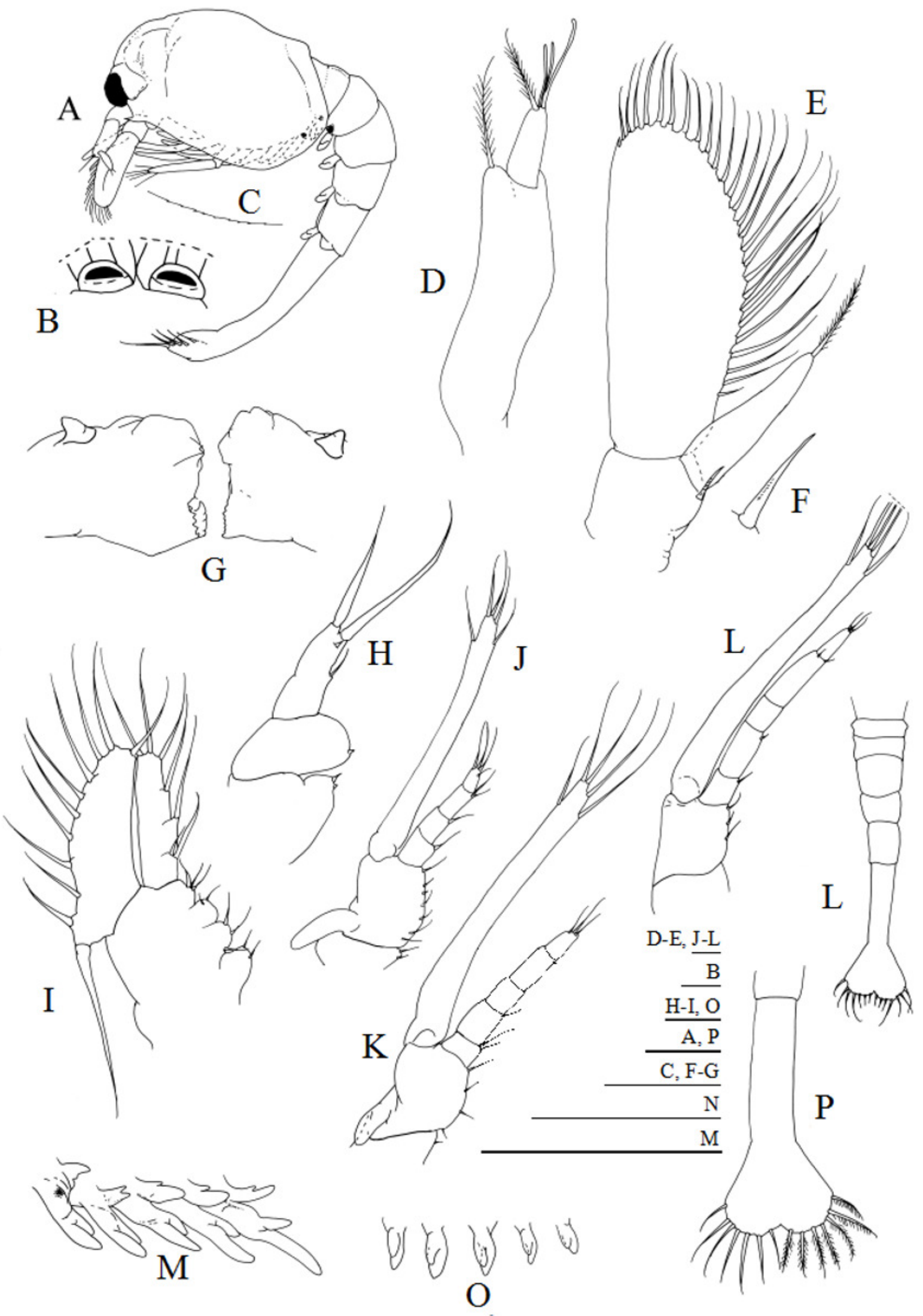




\section{Figure 3}

Second zoea.

Systellaspis debilis . Second zoea: ( A ) total animal, lateral view . (B) detail of carapace anterior ventral margin . (C) antennule . (D) antenna . (E) mandibles . (F) maxillule . (G) detail of maxillule coxal endite . (H) detail of maxillule basial endite . (I) maxilla . (J) first maxilliped . (K) second maxilliped . (L) third maxilliped . (M) first to fifth pereo pods . (N) pleopods . (O) telson. Scale bars: $0.05 \mathrm{~mm}(\mathrm{G}-\mathrm{H}) ; 0.1 \mathrm{~mm}(\mathrm{~A}-\mathrm{F}, \mathrm{I}-\mathrm{L}, \mathrm{O}) ; 1$ $\mathrm{mm}(\mathrm{M}-\mathrm{N})$. 


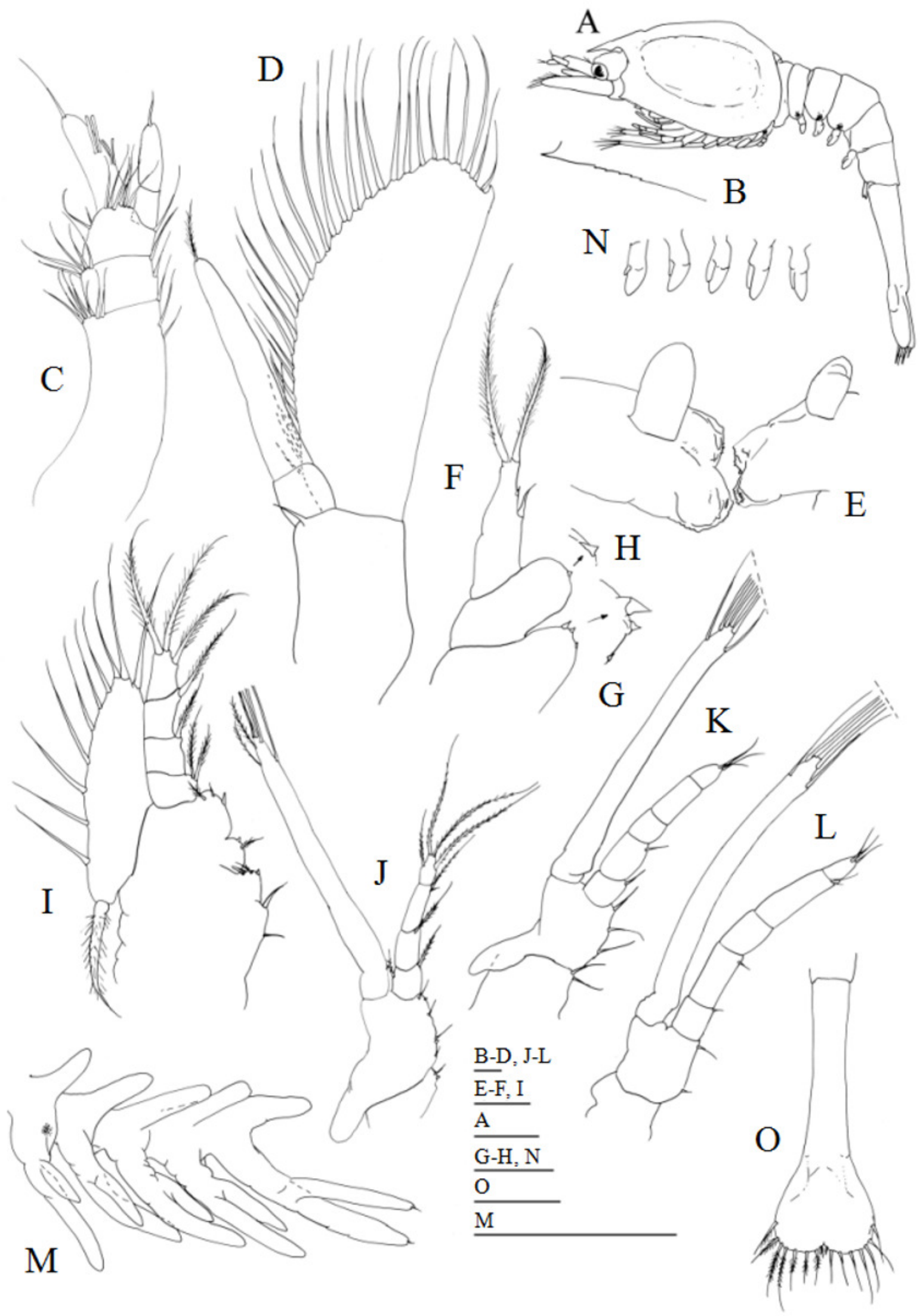




\section{Figure 4}

Third zoea.

Systellaspis debilis. Third zoea: ( A ) total animal, lateral view . (B) detail of carapace anterior ventral margin . (C) antennule . (D) antenna . (E) mandibles . (F) maxillule . (G) detail of maxillule coxal endite . (H) detail of maxillule basial endite . (I) maxilla . (J) first maxilliped . (K) second maxilliped . (L) third maxilliped . (M) first to fifth pereo pods . (N) pleopods . (O) detail of first pleopod exopod posterior margin . (P) detail of second pleopod exopod posterior margin . (Q) detail of third pleopod exopod posterior margin . (R) detail of fourth pleopod exopod posterior margin. (S) detail of fifth pleopod exopod posterior margin . (T) telson and uropods . (U) detail of uropods . (V) detail of uropods endopod posterior margin. Scale bars: $0.05 \mathrm{~mm}(\mathrm{G}-\mathrm{H}$, O- S, V); $0.1 \mathrm{~mm}$ (A- F, I- N, T- U). 


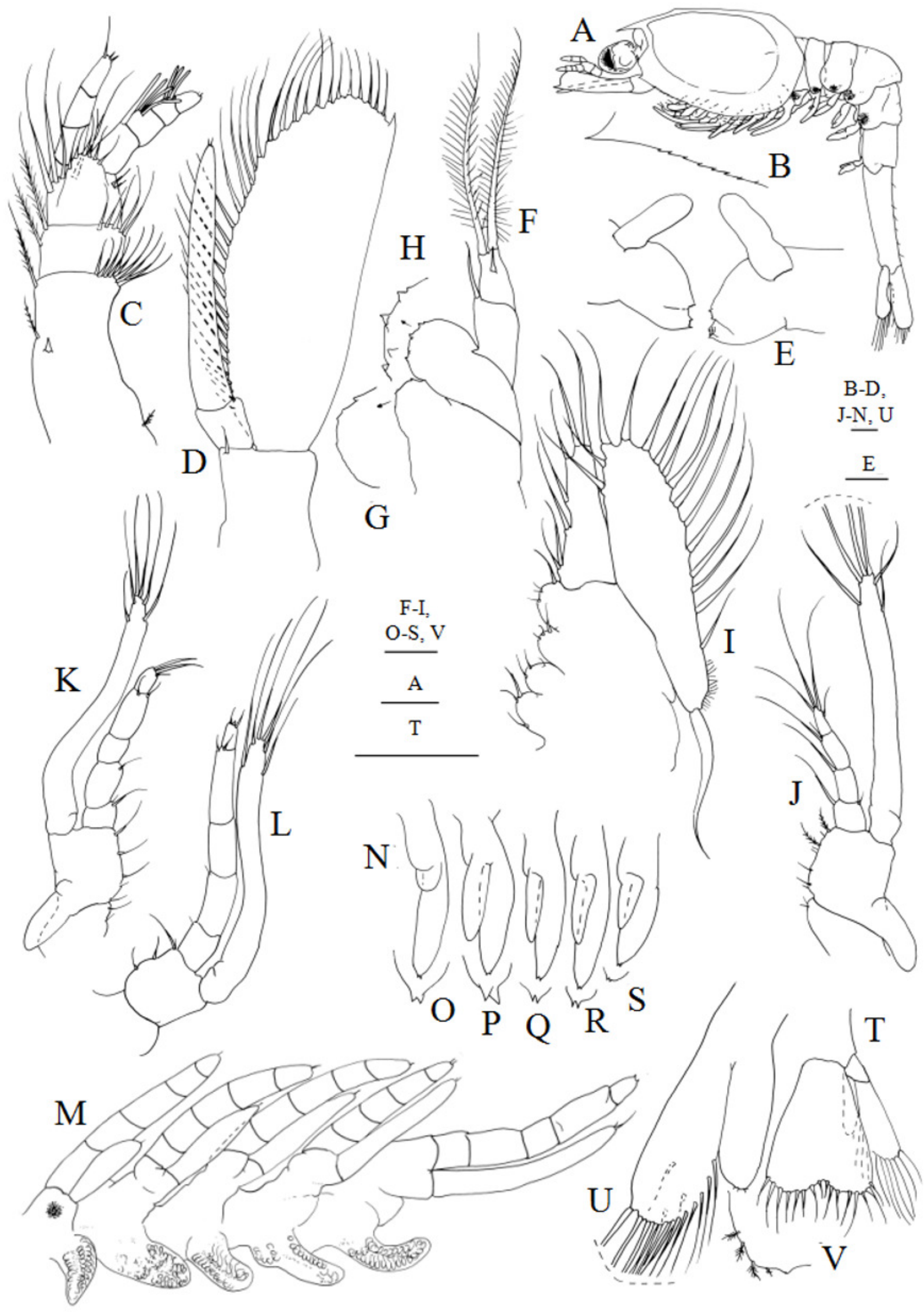




\section{Figure 5}

Fourth zoea.

Systellaspis debilis . Fourth zoea: ( A ) total animal, lateral view . (B) detail of rostrum . (C) antennule . (D) antenna . (E) mandibles . (F) maxillule . (G) maxilla . (H) first maxilliped . (I) second maxilliped . (J) detail of propodus posterior end and dactylus of third maxilliped . (K) first pereo pod . (L) second pereo pod . (M) third pereo pod. (N) fourth pereo pod . (O) fifth pereo pod. (P) detail of fourth pleomere posteromedial margin . (Q) detail of fifth pleomere posterior margin . (R) detail of sixth pleomere posterior margin . (S) pleopods . (T) telson and uropods. Scale bars: $0.1 \mathrm{~mm}$ (A, C- O); $1 \mathrm{~mm}$ (B, P- R, S- T). 


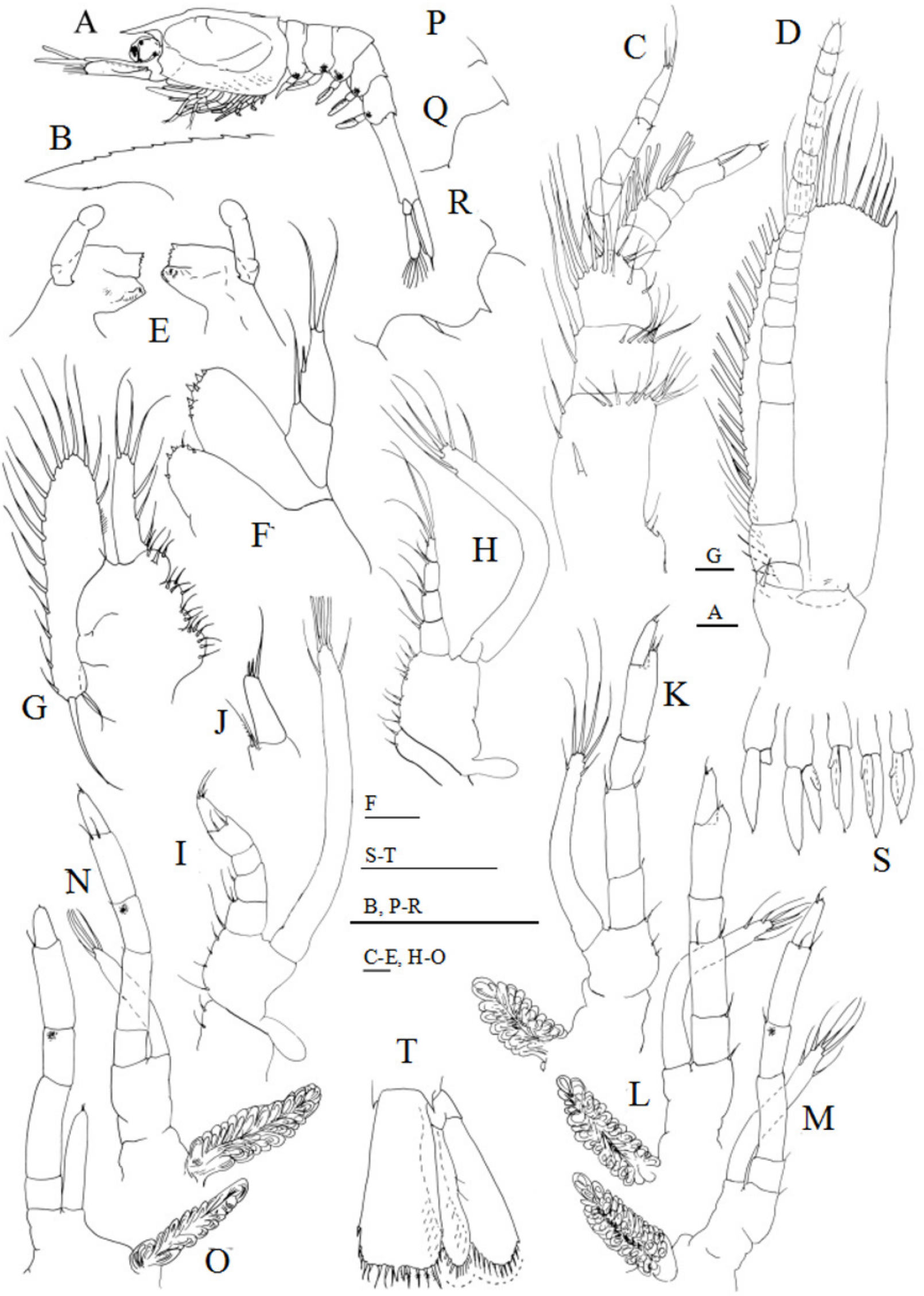




\section{Figure 6}

Decapodid.

Systellaspis debilis . Decapodid: ( A ) total animal, lateral view . (B) detail of rostrum . (C) detail of carapace anterior ventral margin . (D) detail of third pleomere posteromedial margin . (E) detail of fourth pleomere posteromedial margin . (F) detail of fifth pleomere posterior margin . (G) detail of sixth pleomere posterior margin . (H) antennule . (I) antenna . (J) mandibles . (K) maxillule . (L) maxilla . (M) first maxilliped . (N) second maxilliped . (O) third maxilliped . (P) detail of propodus and dactylus of third maxilliped. Scale bars: $0.1 \mathrm{~mm}$ (A, D- P); $1 \mathrm{~mm}$ ( B- C ). 


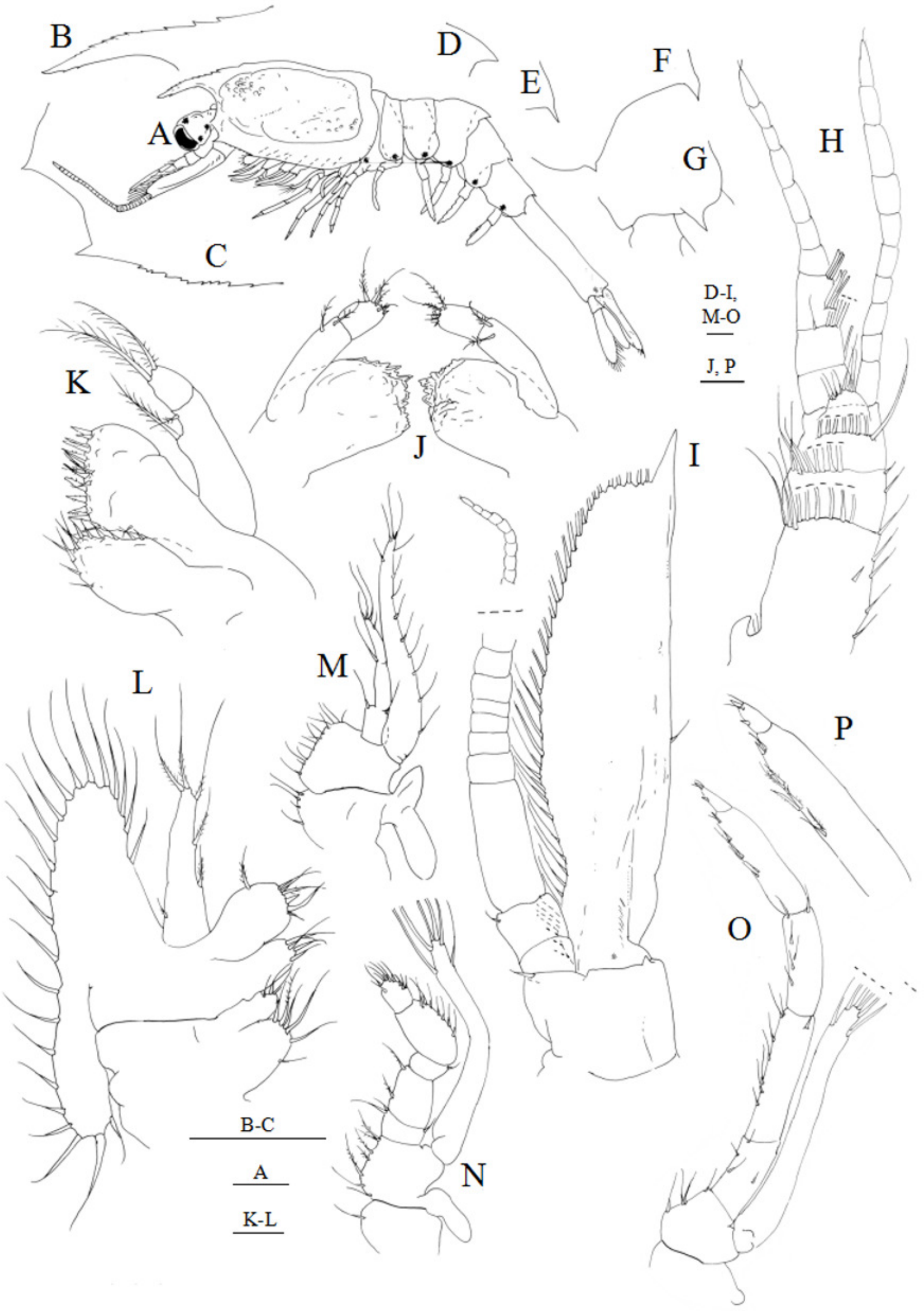




\section{Figure 7}

Decapodid.

Systellaspis debilis . Decapodid: ( A ) first pereo pod. (B) detail of propodus and dactylus of first pereo pod . (C) second pereo pod . (D) detail of propodus and dactylus of second pereo pod . (E) first pereo pod . (F) detail of propodus and dactylus of third pereo pod . (G) fourth pereo pod . (H) fifth pereo pod . (I) detail of propodus and dactylus of fifth pereo pod . (J) first pleopod. (K) first pleopod appendix interna posterior margin, detail of cincinulli . (L) second pleopod . (M) second pleopod appendix interna posterior margin, detail of cincinulli . (N) third pleopod . (O) third pleopod appendix interna posterior margin, detail of cincinulli . (P) fourth pleopod . (Q) fourth pleopod appendix interna posterior margin, detail of cincinulli . (R) fifth pleopod. (S) fifth pleopod appendix interna posterior margin, detail of cincinulli . (T) telson and uropods. Scale bars: $0.05 \mathrm{~mm}$ (K, M, O, Q, S); $0.1 \mathrm{~mm}$ (A- J, L, N, P, R, T). 

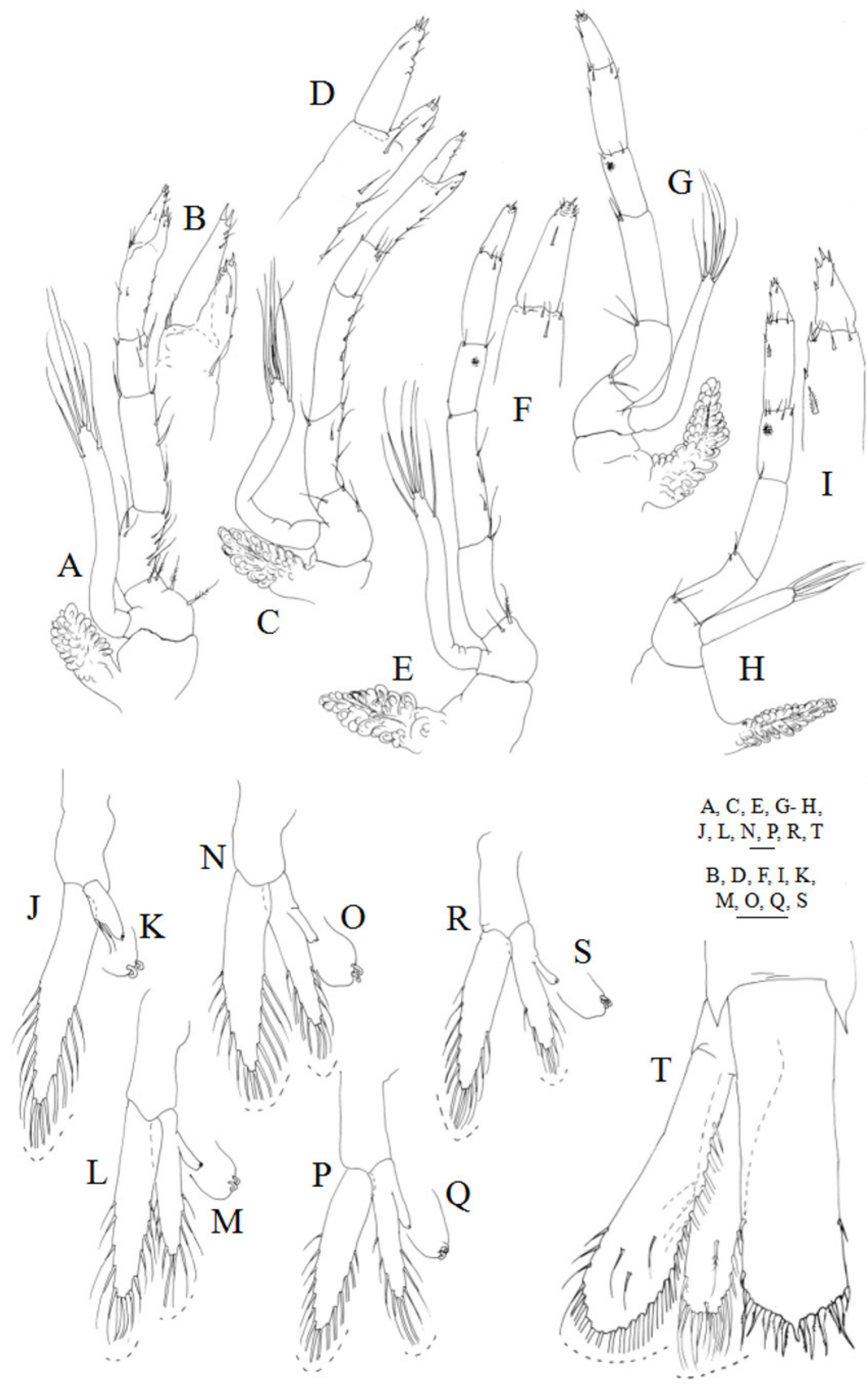


\section{Table $\mathbf{1}$ (on next page)}

Sampled females used in present study.

Sampled females used in present study, per date of collection ; number of eggs ; stage of the eggs - defined as early stage (1), with intense colour and no other pigmentation visible, middle stage (2), with a more pale colour and an embryo having a slight eye pigmentation, and, late stag e (3), almost without colour and with an embryo with the eye pigmentation well visible and developed (adapted from Company \& Sardà, 1997 ) ; size (length, corresponding to the major axis distance $x$ width, corresponding to the minor axis distance, in $\mathrm{mm}$ ) and volume of the eggs ; number of hatchings ; and date of hatching. 


\section{Table 1}

\begin{tabular}{|c|c|c|c|c|c|c|c|}
\hline Female & Date of collection & Nr of eggs & $\begin{array}{l}\text { Stage of } \\
\text { the eggs }\end{array}$ & $\begin{array}{c}\text { Size of the eggs } \\
\text { (in mm) }\end{array}$ & $\begin{array}{l}\text { Volume of the } \\
\text { eggs }\left(\text { in } \mathrm{mm}^{-3}\right)\end{array}$ & $\begin{array}{c}\text { Nr of } \\
\text { hatchings }\end{array}$ & $\begin{array}{c}\text { Date of } \\
\text { hatching }\end{array}$ \\
\hline 1 & $15 / 08 / 10$ & 12 & 1 & $3.4-3.6 \times 1.9-2.1$ & $6.43-8.31$ & 0 & - \\
\hline 2 & $15 / 08 / 10$ & 8 & 3 & $3.6 \times 2.1$ & 8.31 & 5 & $20 / 08 / 10$ \\
\hline 3 & $15 / 08 / 10$ & 9 & 3 & $3.5-3.6 \times 2.1$ & $8.08-8.31$ & 2 & 7 to $8 / 09 / 10$ \\
\hline 4 & $15 / 08 / 10$ & 7 & 1 & $3.6-3.8 \times 2.0$ & $7.54-7.96$ & 0 & - \\
\hline 5 & $15 / 08 / 10$ & 10 & 2 & $3.5 \times 2.0$ & 7.33 & 4 & $21 / 09 / 10$ \\
\hline 6 & $28 / 06 / 11$ & 9 & 3 & $3.7 \times 2.0$ & 7.75 & 8 & 1/07/11 \\
\hline 7 & $28 / 06 / 11$ & 7 & 2 & $3.5-3.9 \times 2.0$ & $7.33-8.17$ & 6 & $25 / 07 / 11$ \\
\hline 8 & $28 / 06 / 11$ & 3 & 2 & 3. $6-3.9 \times 2.0$ & $7.54-8.17$ & 0 & - \\
\hline 9 & $28 / 06 / 11$ & 2 & 2 & $3.5-3.9 \times 2.1$ & $8.08-9.01$ & 0 & - \\
\hline 10 & $29 / 06 / 11$ & 11 & 2 & $3.6 \times 2.1$ & 8.31 & 1 & 29/07/11 \\
\hline 11 & $21 / 06 / 11$ & 12 & 3 & $3.7 \times 2.0$ & 7.75 & 9 & 4 to $6 / 07 / 11$ \\
\hline 12 & $28 / 06 / 11$ & 10 & 2 & $3.5-4.0 \times 2.0$ & $7.33-8.38$ & 8 & $25 / 07 / 11$ \\
\hline 13 & $21 / 06 / 11$ & 12 & 3 & $3.6-3.9 \times 2.0$ & 7.54- 8.17 & 10 & 8 to $9 / 07 / 11$ \\
\hline & & $\begin{array}{c}\text { Total: } \\
112\end{array}$ & - & $\begin{array}{c}\text { Average: } \\
3.65 \pm 0.09 \times 2.0 \pm 0.05\end{array}$ & $\begin{array}{l}\text { Average: } \\
7.90 \pm 0.53\end{array}$ & $\begin{array}{c}\text { Total: } \\
53\end{array}$ & - \\
\hline
\end{tabular}

2 